\title{
Performance Study of Silicon-Based Multi-Junction Solar Cell
}

\section{Kamrunnahar Kali1, Mohammad Ashraful Islam², Must. Asma Yasmin³, Sangita Das1, Komol Kanta Sharker ${ }^{4}$}

\author{
${ }^{1}$ Department of Physics, Comilla University, Cumilla, Bangladesh \\ ${ }^{2}$ Department of Physics, University of Chittagong, Chattogram, Bangladesh \\ ${ }^{3}$ Department of Computer Science and Engineering, Bangladesh Army University of Engineering and Technology, \\ Natore, Bangladesh \\ ${ }^{4}$ Department of General Educational Development, Daffodil International University, Dhaka, Bangladesh \\ Email: Kamrunkali@yahoo.com, asharifphys@gmail.com, asma.yasmin.cu@gmail.com, sangitadas.cu.07.11@gmail.com, \\ sharkerkomol@diu.edu.bd
}

How to cite this paper: Kali, K., Islam, M.A., Yasmin, M.A., Das, S. and Sharker, K.K. (2019) Performance Study of Silicon-Based Multi-Junction Solar Cell. Computational Water, Energy, and Environmental Engineering, 8, 91-98.

https://doi.org/10.4236/cweee.2019.84006

Received: June 30, 2019

Accepted: September 13, 2019

Published: September 16, 2019

Copyright $\odot 2019$ by author(s) and Scientific Research Publishing Inc. This work is licensed under the Creative Commons Attribution International License (CC BY 4.0)

http://creativecommons.org/licenses/by/4.0/

\begin{abstract}
This paper presents a performance study of silicon-based multi-junction (MJ) solar cell which is produced by Spectrolab is the most efficient solar cell in the world, with a record efficiency of over $40 \%$. The I-V characteristics of solar cells were investigated for different environmental conditions (both at indoor and outdoor). Photovoltaic (PV) parameters like short circuit current $\left(\mathrm{I}_{\mathrm{SC}}\right)$, open circuit voltage $\left(\mathrm{V}_{\mathrm{OC}}\right)$, fill factor $(\mathrm{FF})$ and efficiency $(\eta)$ were evaluated for the fabricated cell. The fabricated cell provides I-V characteristics curve which shows that the maximum efficiency of the cell is obtained when the cell temperature is lower. It was also observed that, efficiencies of the cells are about $17 \%$ to $24 \%$ at indoor and $7 \%$ to $20 \%$ at outdoor and fill factors are 0.40 to 0.71 . From the result, it can also be found that fill factor is directly affected by the values of the cells series and shunt resistance.
\end{abstract}

\section{Keywords}

Multijunction (MJ) Solar Cell, Photovoltaic Performance, Efficiency Enhancement

\section{Introduction}

Energy plays a crucial role in human activities and has gradually become the foundation of modern economy all over the world. Due to prevalently utilizing fossil fuels, global warming and energy crisis are getting increasingly serious, resulting in an urgent research and development of solar energy [1]. The energy 
achieved from the Sun is an abundant and nonpolluting source of energy. Most cells that are produced on the photovoltaic markets are based on silicon wafers due to the abundance and mature technology of silicon. The efficiency of single junction silicon solar cells has rapidly improved over the last two decades [2] [3] [4] [5] [6]. Solar energy is an environment pollution free unlimited renewable source of energy and can be converted into electrical energy using solar cell. However, the conversion efficiency of solar cell is very poor, that is, mainly caused by carrier recombination loss as well lower and higher energy photons absorption losses [7]. Photovoltaic technologies have become increasing attractive and competitive in recent years as a renewable alternative to traditional fossil fuel energy sources. Among the many currently available PV technologies, multi-junction PV solar cells produce the highest energy conversion efficiencies exceeding the Shockley-Queisser limit [2] [8]. MJ solar cells split up the solar spectrum by vertically stacking subcells comprised of different energy bandgaps in order to more efficiently convert energy from the solar spectrum. The MJ solar cells structure is composed of number of cells in which the bandgaps of the subcells are divided by tuning the composition. For efficient absorption of whole solar energies, the higher bandgapsub cell is fabricated at the top and others are below the top subcell [9]. The silicon solar cell's technological improvements resulted in the achievement of the $25 \%$ record efficiency on lab scale and of $22 \%$ in production [2], very close to the theoretical maximum efficiency for a single junction PV device of $31 \%$. Several solar cell approaches have been proposed like MJ solar cell, concentrator solar cell, intermediate bandgap solar cell, quantum well and quantum dot solar cells etc. Among these, the MJ approach is very much attractive to resolve the main issues associated with efficiency degradation [10]. The Single junction cell has the limitation that it cannot absorb low energy photons and as such has relatively low efficiency. To overcome this limitation, MJ solar cells, such as double and triple junction solar cells, based on the spectral splitting principle have been devised.

\section{Experimental Method}

In this work, a digital pyranometer has been used to measure the solar radiation. The resulting equivalent circuit of a solar cell is shown in Figure 1.

The I-V characteristics of such a device are given by,

$$
I=I_{s}\left\{\exp \left[\frac{q V}{K T}\right]-1\right\}-I_{L}
$$

where, $I_{L}$ is photo generated current (amperes), $q$ is elementary charge, $1.6 \times 10^{-19}$ Coulombs, $k$ is Boltzmann's constant, $1.38 \times 10^{-23} \mathrm{~J} / \mathrm{K}, T$ is the cell temperature in Kelvin. At $25^{\circ} \mathrm{C}, \mathrm{kT} / \mathrm{q} \approx 0.0259$ volts.

Fill factor is the ratio of the maximum power point divided by the open circuit voltage $\left(V_{o c}\right)$ and the short circuit current $\left(I_{s c}\right)$ :

$$
F F=\frac{P_{m}}{V_{o c} \times I_{s c}}=\frac{\eta \times A_{c} \times E}{V_{o c} \times I_{s c}}
$$




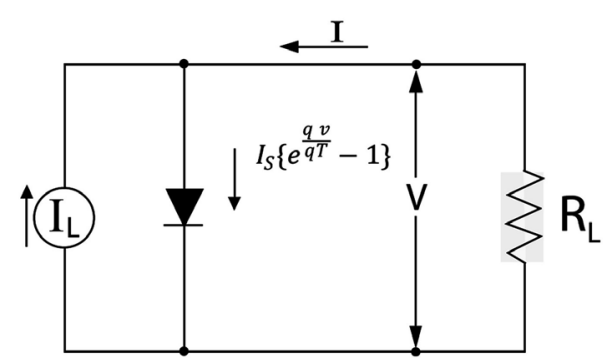

Figure 1. The equivalent circuit of a solar cell.

where, $\eta$ is the solar cell conversion efficiency, $A_{c}$ is the surface area of the solar cell, $E$ is the input light irradiance.

$F F$ can also be interpreted graphically as the ratio of the rectangular areas depicted in Figure 2.

$$
F F=\frac{P_{\mathrm{MAX}}}{P_{T}}=\frac{I_{m} V_{m}}{I_{s c} V_{c}}
$$

Efficiency is the ratio of the electrical power output $P_{\text {out }}$ compared to the solar power input, $P_{\text {in }}$, into the PV cell. $P_{\text {out }}$ can be taken to be $P_{\mathrm{MAX}}$ since the solar cell can be operated up to its maximum power output to get the maximum efficiency

$$
\eta=\frac{P_{\text {out }}}{P_{\text {in }}}, \eta_{\mathrm{MAX}}=\frac{P_{\mathrm{MAX}}}{P_{\text {in }}}
$$

$P_{\text {in }}$ is taken as the product of the irradiance of the incident light, measured in $\mathrm{W} / \mathrm{m}^{2}$, with the surface area of the solar cell which is measured in $\mathrm{m}^{2}$.

STC specifies a temperature of $25^{\circ} \mathrm{C}$ and an irradiance of $1000 \mathrm{~W} / \mathrm{m}^{2}$ with an air mass 1.5 (AMI 1.5) spectrum.

\section{Results and Discussion}

The current-voltage characteristics of the solar cell are measured at different indoor and outdoor conditions. The solar cell has been characterized by using the experimental set and also characterized both in the indoor and outdoor conditions. Figures 3(a)-(d) shows the variation of current with voltage when the cell is illuminated with the light source and the sun. The shapes of the curves are shown in Figures 3(a)-(d). In the I-V characteristics curve, it was observed that the current remains constant at the beginning and there is small variation of current with voltage in short time. At the end of the graph, it shows that current changes rapidly with small change in voltage. Figures 3(a)-(d) shows the current-voltage characteristics curves of solar cell at different light intensities. The $V_{o c}$ and $I_{s c}$ can be directly determined from graph, the maximum voltage $V_{m}$ and current $I_{m}$ at the maximum power point can be determined by computing the IV product at the turning points on the curve and selecting the points where the product is maximum. Thus the maximum power and fill-factor can be obtained from the relations $P_{m}=I_{m} V_{m}$ and $F F=I_{m} V_{m} /$ VocIsc, respectively. The efficiency of the cell can also be obtained from this graph, if it compare the maximum output power with the incident input power. By analyzing the various kinds of 
situation of the solar cell, it was observed that from this characteristics curve the maximum efficiency of the cell is obtained when the cell temperature is lower. From this I-V characteristic curves it was concluded that, the curve which becomes more square shape gives high efficiency.

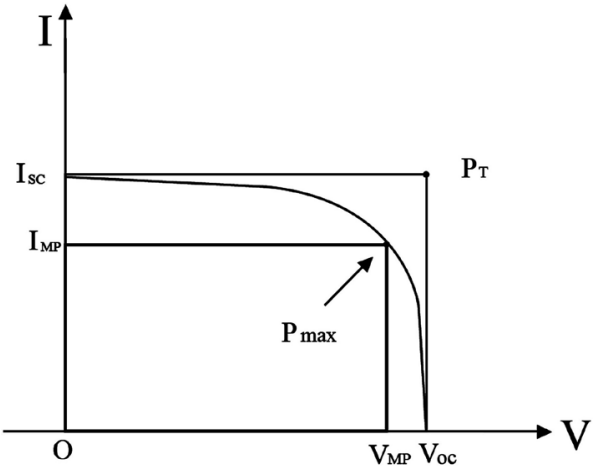

Figure 2. Getting the Fill Factor from the I-V curve.

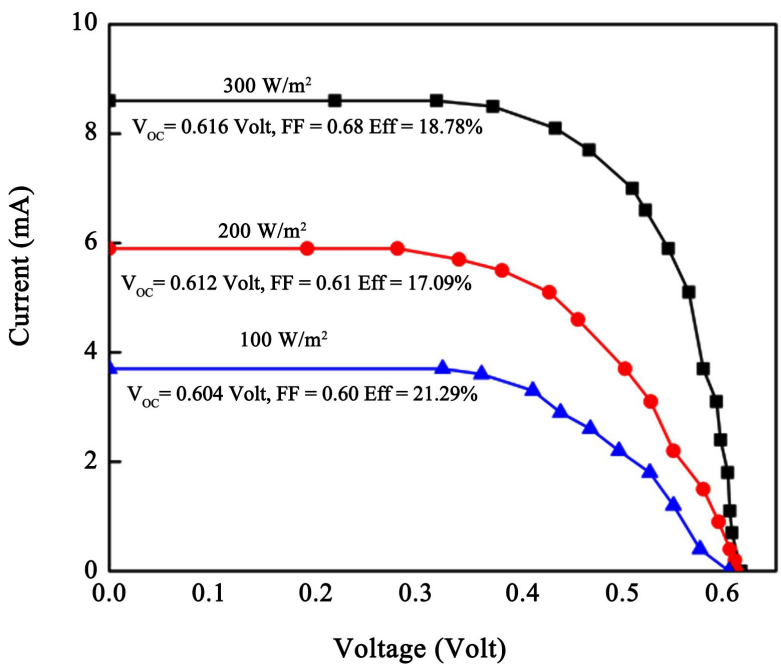

(a)

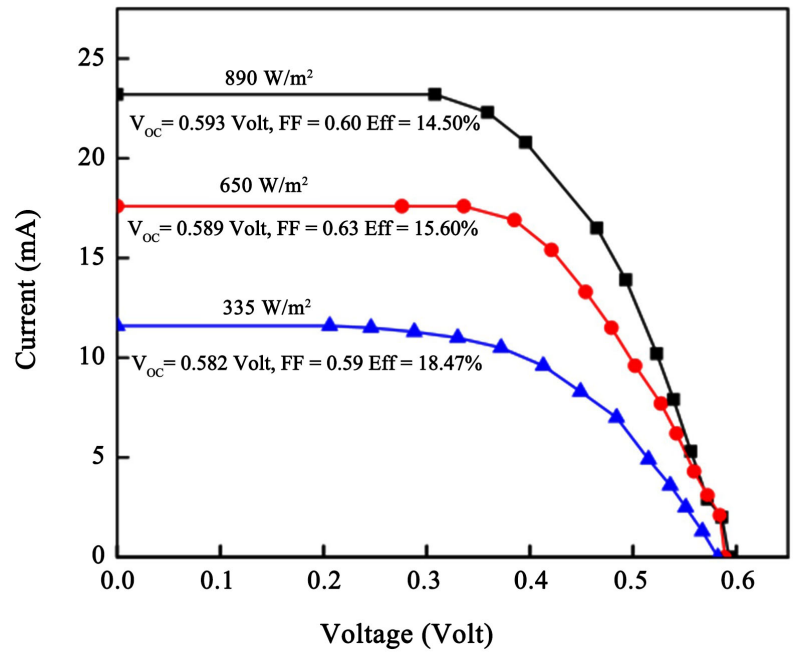

(b) 


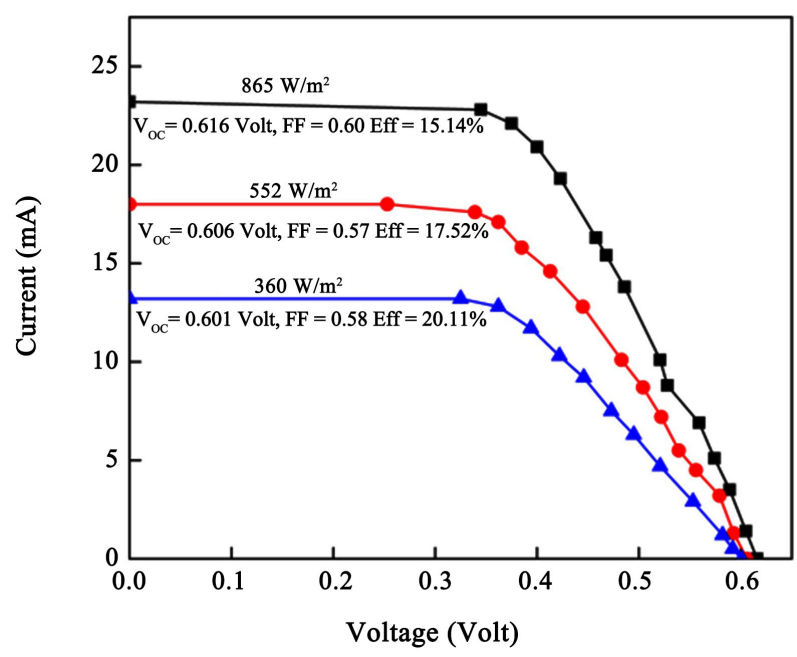

(c)

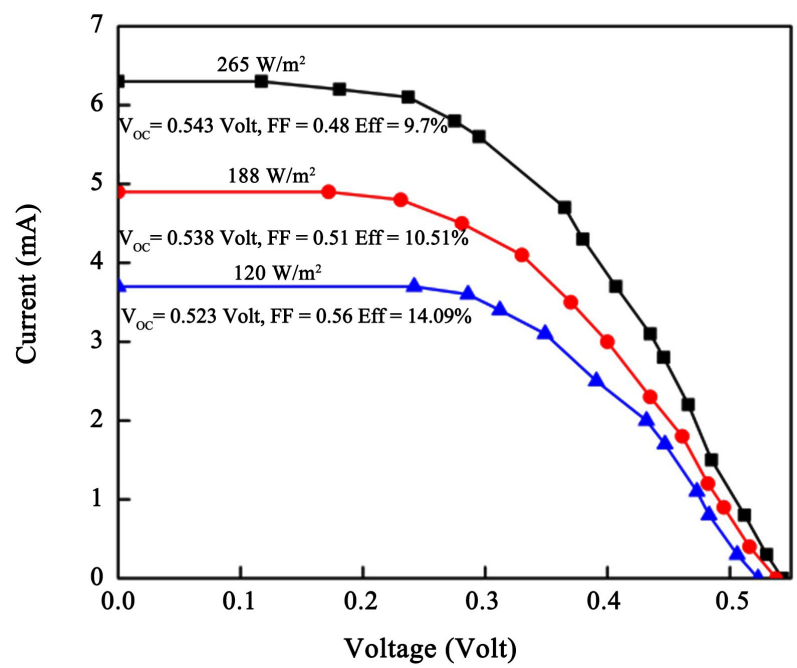

(d)

Figure 3. Voltage-Current characteristics of solar cell at different light intensities (a) 300 W, $200 \mathrm{~W}, 100 \mathrm{~W}$ bulb as a constant light source, (b) When the sky was clear (sunny day), (c) Sun as a light source when the sky was windy, (d) When the sky was cloudy.

Figure 4 shows that if we compare the maximum point in the $\mathrm{P}-\mathrm{V}$ curve and the maximum power point in the I-V curve, it results that they are situated at the same vertical line.

The ideal characteristics of solar cells is obtained by plotting corresponding fill factor (FF) of normalized open-circuit voltage [Voc/(KT/q)] and its logarithmic are shown in Figure 5(a) and Figure 5(b), respectively, where the first one shows a non-linear behavior bowing upward and the second one exhibits linear relationship.

The graph shown in Figure 6 is the spectral response of a -Si: Hmultijunction solar cell. In the graph, it rises sharply at the beginning for short wavelengths and reaches to its maximum value and then decreases for longer wavelengths. The maximum peak of spectral sensitivity is found to occur at $0.55 \mu \mathrm{m}$ which lies in visible range. Solar spectrum has maximum intensity at $0.5 \mu \mathrm{m}$ range. 


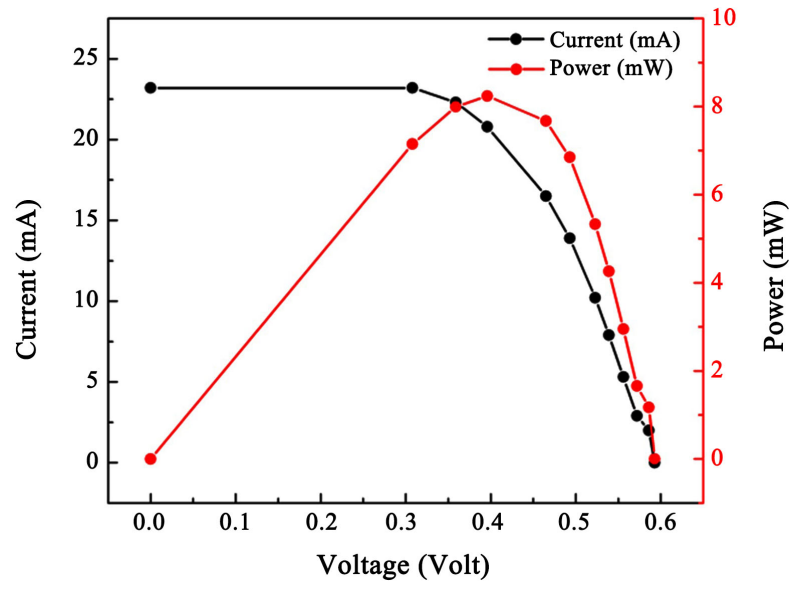

Figure 4. Current and Power as a function of Voltage.

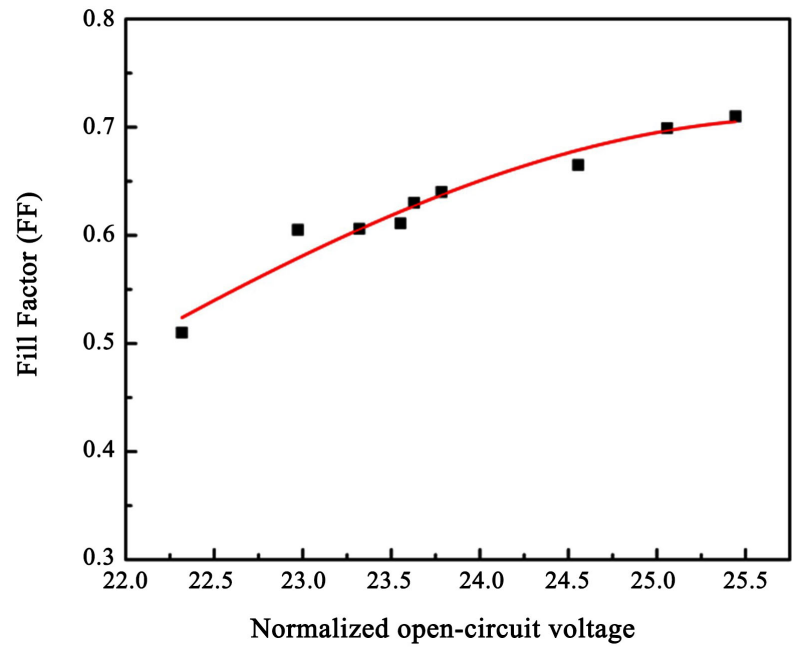

(a)

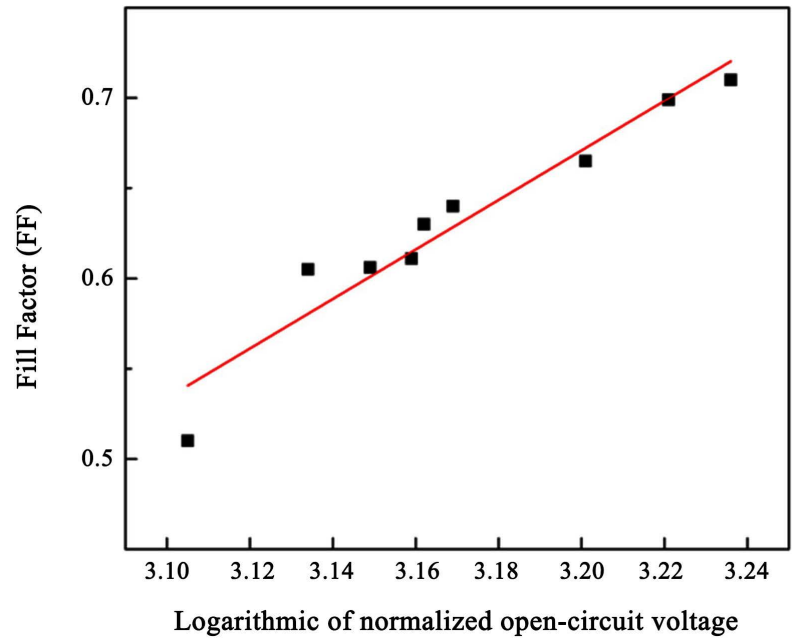

(b)

Figure 5. (a) Value of the fill factor as a function the open-circuit voltage normalized to the thermal voltage, (kT/q); (b) Value of the fill factor as a function of the logarithmic open-circuit voltage normalized to the thermal voltage, (kT/q). 


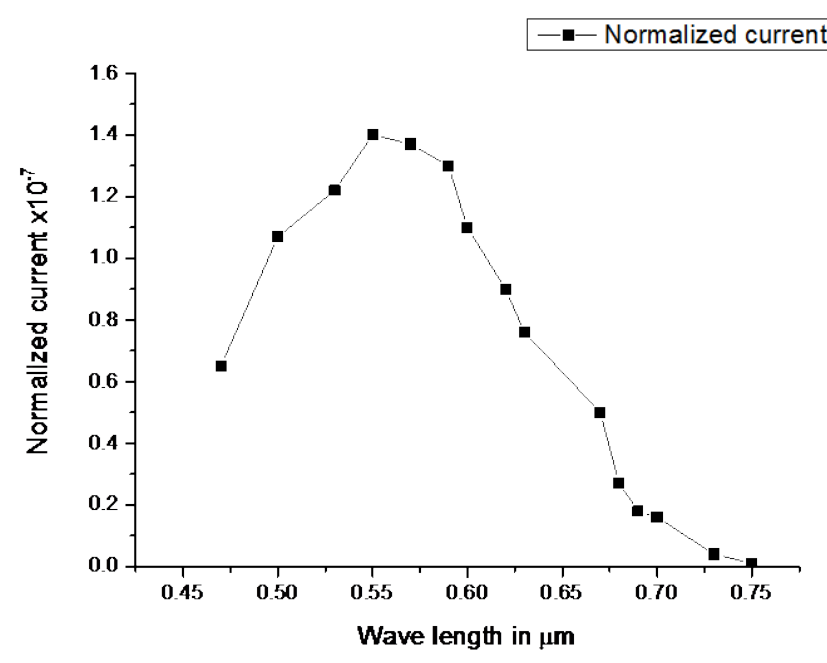

Figure 6. Spectral response of a multijunction solar cell.

\section{Conclusion}

In this work, the efficiency of MJSC is evaluated at different light intensities on various times of the day. At the more insulation, more current and more voltage are produced. Variation of efficiency, open circuit voltage $\left(V_{o c}\right)$, short circuit current $\left(J_{s c}\right)$ and fill factor $(F F)$ with the variation of different light intensity have been investigated. When the cell temperature becomes high, its efficiency decreases. Due to wind effect, cell temperature becomes low and more efficiency is obtained. As the temperature increases, the diffusion length increase, because the diffusion constant stays the same or increase with temperature, and the minority life time increase with temperature. The increase in minority-carrier diffusion length causes an increase in $J_{L}$ (photo-generated current density). This effect causes a reduction of efficiency as the temperature increases. The main impact of series resistance is to reduce the fill factor, although excessively high values may also reduce the short -circuit current. A large fill factor is desirable and corresponds to an I-V sweep that is more square-like. Typical fill factors range from 0.5 to 0.82 . The fill factor is directly affected by the values of the cells series and shunt resistance. Increasing the shunt resistance $\left(\mathrm{R}_{\mathrm{sh}}\right)$ and decreasing the series resistance $\left(R_{s}\right)$ will lead to higher fill factor, thus resulting in greater efficiency, and pushing the cells output power closer towards its theoretical maximum.

\section{Acknowledgements}

Authors thank Dr. Md. Nurul Islam, Dept. of Physics, University of Chittagong for helpful discussions.

\section{Conflicts of Interest}

The authors declare no conflicts of interest regarding the publication of this paper. 


\section{References}

[1] Da, Y., Xuan, Y. and Li, Q. (2016) From Light Trapping to Solar Energy Utilization: A Novel Photovoltaic Thermoelectric Hybrid System to Fully Utilize Solar Spectrum. Energy, 95, 200-210. https://doi.org/10.1016/j.energy.2015.12.024

[2] Green, M.A., Emery, K., Hishikawa, Y., Warta, W. and Dunlop, E.D. (2012) Solar Cell Efficiency Tables (Version 39). Progress in Photovoltaics. Research and Applications, 20, 12-20. https://doi.org/10.1002/pip.2163

[3] Green, M.A. (2003) Crystalline and Thin-Film Silicon Solar Cells: State of the Art and Future Potential. Solar Energy, 74, 181-192. https://doi.org/10.1016/S0038-092X(03)00187-7

[4] Blakers, A.W. and Green, M.A. (1986) 20\% Efficient Silicon Solar Cell. Applied Physics Letters, 48, 215-217. https://doi.org/10.1063/1.96799

[5] Green, M.A. (2009) The Path to 25\% Silicon Solar Cell Efficiency: History of Silicon Cell Evolution. Progress in Photovoltaics, 17, 183-189. https://doi.org/10.1002/pip.892

[6] Zhao, J., Wang, A. and Green, M.A. (2001) 24.5\% Efficiency PERT Silicon Solar Cells on SHE MCZ Substrates and Cell Performance on Other SHE CZ and FZ Substrates. Solar Energy Materials \& Solar Cells, 66, 27-36. https://doi.org/10.1016/S0927-0248(00)00155-0

[7] Green, M.A. (2002) Limiting Photovoltaics Light Conversion Efficiency. Progress in Phtovoltaic, 9, 257-261. https://doi.org/10.1002/pip.375

[8] King, R.R., Law, D.C., Edmondson, K.M., Fetzer, C.M., Kinsey, G.S., Yoon, H., Sherif, R.A. and Karam, N.H. (2007) 40\% Efficient Metamorphic GaInP/GaInAs/Ge Multijunction Solar Cells. Applied Physics Letters, 90, Article ID: 183516. https://doi.org/10.1063/1.2734507

[9] Islam, M.R., Hasan, M.T., Bhuiyan, A.G., Islam, M.R. and Yamamoto, A. (2008) Design and Performance of $\operatorname{In}_{\mathrm{x}} \mathrm{Ga}_{1-\mathrm{x}} \mathrm{N}$-Based MJ Solar Cells. IETECH Journal of Electrical Analysis, 2, 237-243.

[10] Islam, M.R., Hasan, M.T., Rayhan, M.A. and Bhuiyan, A.G. (2012) High Efficiency $\mathrm{In}_{\mathrm{x}} \mathrm{Ga}_{1-\mathrm{x}} \mathrm{N}$-Based Multi-Junction Solar Cells with Concentrator. Journal of Electrical Engineering, 33, 8271-8277. 